DOI: https://doi.org/10.12957/teias.2020.48628

\title{
OS MOVIMENTOS CIBERATIVISTAS DE (RE)EXISTÊNCIA NAS REDES SOCIAIS E SUAS IMPLICAÇÕES PARA A EDUCAÇÃO
}

Dilton Ribeiro Couto Junior

Luciana Velloso

Rosemary dos Santos

\section{Resumo}

Com a emergência das possibilidades interativas engendradas pelo digital, deixamos de ser meros receptores de informação e passamos a ter a oportunidade também de produzir e compartilhar conteúdos diversos para outras/os internautas. Este novo contexto nos inspira a repensar o cenário político contemporâneo e os usos das tecnologias digitais, cuja especificidade na produção e no compartilhamento de dados informacionais rompe com a centralidade da mídia de massa. Diante disso, o presente artigo tem como objetivo investigar o ciberativismo de mulheres na rede social, focalizando os debates que emergiram em torno do movimento \#ELENÃO, que envolveu a participação de milhões de internautas de todos os cantos do Brasil em setembro de 2018 em questionamento à campanha política do presidenciável Jair Bolsonaro. Esse movimento de (re)existência orquestrado por mulheres na rede traz implicações para o campo da educação, principalmente quando reconhecemos o Facebook enquanto um importante espaço de mobilização social.

Palavras-chave: ciberativismo; política brasileira; feminismo.

\section{CIBERACTIVIST MOVEMENTS OF RESISTANCE/EXISTENCE IN SOCIAL NETWORKS AND THEIR IMPLICATIONS TO THE EDUCATION}

Abstract

With the emergence of interactive possibilities generated from digital resources, we are no longer mere receivers of information, but we also have the opportunity to produce and share diverse contents for others Internet users. Such new context inspires us to rethink the contemporary political scenario and the uses of digital technologies whose specificity in the production and sharing of data information breaks with the centrality of mass media. In face of this context, the objective of this article is to investigate the women's cyberactivism in the social network, focusing on the reflective efforts of the \#ELENÃO [\#NOTHIM in English] movement, which involved the participation of millions of Internet users from all around Brazil in September of 2018 as a questioning of the political campaign of the presidential candidate Jair Bolsonaro. This movement of resistance/existence organized by women in the network has implications for the education field, especially when we recognize Facebook as a space for social mobilization.

Keywords: ciberactivism; brazilian politics; feminism.

\section{LOS MOVIMIENTOS CIBERACTIVISTAS DE (RE)EXISTENCIA EN LAS REDES SOCIALES Y SUS IMPLICACIONES PARA LA EDUCACIÓN}

\section{Resumen}

Con la emergencia de las posibilidades interactivas engendradas por el digital, dejamos de ser solamente receptores de información y pasamos a tener la oportunidad también de producir y compartir contenidos diversos para otras/os internautas. Este nuevo contexto nos inspira a repensar el escenario político contemporáneo y los usos de las tecnologías digitales cuya especificidad en la producción y en intercambio de datos informativos rompen con la centralidad de los medios masivos. Ante eso, el presente artículo tiene como objetivo investigar el ciberactivismo de mujeres en la red social, enfocando los debates que emergieron en torno al movimiento \#ELENÃO, que involucró la participación de millones de internautas de todos los 
rincones de Brasil en septiembre de 2018, en cuestionamientos a la campaña política del presidenciable Jair Bolsonaro. Este movimiento de (re)existencia orquestado por mujeres en la red trae implicaciones para el campo de la educación, principalmente cuando reconocemos a Facebook como un importante espacio de movilización social.

Palabras clave: ciberactivismo; política brasileña; feminismo.

\title{
INTRODUÇÃO
}

\author{
Cadê meu celular? \\ Eu vou ligar prum oito zero \\ Vou entregar teu nome \\ E explicar meu endereço \\ Aqui você não entra mais \\ Eu digo que não te conbeço \\ E jogo água fervendo \\ Se você se aventurar \\ Eu solto o cachorro \\ E, apontando pra você \\ Eu grito: péguix guix guix guix \\ Eu quero ver \\ Vocêpular, você correr \\ $\mathrm{Na}$ frente dos vizinhos \\ Cêv vai se arrepender de levantar \\ A mão pra mim ${ }^{1}$ \\ Elza Soares
}

Com trecho da canção de Elza Soares, Maria da Vila Matilde (2016), tratamos de abrir alas para discutir um tema tão atual e que tanto tem nos mobilizado: os movimentos ciberativistas de (re)existência nas redes sociais. O fragmento inicial Cadê meu celular? Eu vou ligar prum oito žró ${ }^{2}$ atrelado ao final da citação Cê vai se arrepender de levantar a mão pra mim, representam muito do que pretendemos analisar em nossas discussões com este texto. Partimos do pressuposto de que o espaço da internet e dos diferentes dispositivos digitais têm se constituído estruturantes no debate de questões ligadas à intolerância, preconceito, misoginia e tantos fenômenos que observamos pulular em nossas redes e relações cotidianas.

Ao longo do texto, desejamos operar conceitualmente com o ciberativismo feminino a partir, inicialmente, do caso do grupo Mulheres unidas contra Bolsonaro ${ }^{3}$ que, no período das eleições de 2018, reuniu mais de 2,5 milhões de apoiadoras desfavoráveis às propostas políticas do presidenciável. O fenômeno é analisado por diferentes pesquisadoras, como Abreu, Dorneles e Gonçalves (2018):

Dois mil e dezoito, eleições presidenciais no Brasil. Que esta não seria uma disputa tranquila e sem sobressaltos todo mundo já imaginava. Que traria muito dos protestos de 2013 para cá, também. Talvez o que ninguém poderia prever é

\footnotetext{
${ }^{1}$ Fonte: https://www.youtube.com/watch?v=y6V8IL8xn7g. Acesso em 2 out. 2018.

$2 \mathrm{O}$ número 180 citado neste trecho da música é uma menção à Central de Atendimento à Mulher, que funciona como disque-denúncia da Secretaria Especial de Políticas para as Mulheres (SPM), da Igualdade Racial e dos Direitos Humanos. São atendentes mulheres que lidam especificamente com casos de violência contra mulheres, prestando todo apoio que demandarem. Fonte: https://bit.ly/2PuhXVR. Acesso em 1 out. 2018.

${ }^{3}$ Fonte: https://bit.ly/2IKhY5u. Acesso em 20 set. 2018.
} 
que 2,5 milhões de mulheres, cis e trans, de direita e de esquerda, brancas e negras, militantes e mais observadoras, fariam muito barulho e incomodariam muita gente ${ }^{4}$.

Entendemos que este movimento merece nossa atenção pela amplitude que recebeu, muito em função da difusão de debates ligados ao movimento feminista, que encontrou nas redes sociais narrativas que se materializaram e instituíram mudanças nas ruas, nas escolas e nas universidades, fazendo ressoar seu eco cada vez mais presentes. Tais movimentos que articulam os anseios de diferentes grupos sociais, contudo, já possuem toda uma trajetória apresentada por Castells (2013), que analisa o poder dos movimentos sociais e suas repercussões nos espaços da internet, exercendo verdadeiros locus de contrapoder, mediante processos de comunicação autônoma e se constituindo como resistências aos detentores do poder institucional. De acordo com o autor, "[...] os cidadãos da era da informação tornam-se capazes de inventar novos programas para suas vidas com as matérias-primas de seu sofrimento, suas lágrimas, seus sonhos e esperanças. [...] Superam a impotência de seu desespero solitário colocando em rede seu desejo" (CASTELLS, 2013, p. 14).

As redes sociais configuram-se como importantes canais de informação e comunicação, mas também, como canais de circulação e criação significativa de debates entre as/os internautas de todos os cantos do país sobre os mais variados temas. O ciberespaço tem como característica marcante a complexidade das redes e dos artefatos que circulam livremente, no qual a cultura política também se modifica e se insere nesse novo contexto em permanente transformação. A liberação do polo de emissão (LEMOS, LÉVY, 2010) permite a troca de informação, assim como o surgimento de novos agentes e novas mediações por meio de questões que atingem, sobretudo, a dimensão política.

Dessa forma, os debates políticos se inserem em um novo formato de ação na sociedade, que tem como potência as tecnologias digitais. Conforme Lemos e Lévy (2010), o ciberespaço, cenário privilegiado da cibercultura, é em sua essência político e o futuro da internet aponta para novas modalidades de emissão livre, de formas de compartilhamento de informação, de cooperação. Frente a isso, os autores argumentam que as mudanças globais da esfera política vão em direção a uma ciberdemocracia (LEMOS; LÉVY, 2010). Diante do intercâmbio de experiências agregando usuárias/os de diversos contextos socioculturais, não podemos negar o quanto as redes sociais constituem-se enquanto "[...] uma grande arena de encontro, de diálogo e de produção de sentidos" (MACEDO, PEREIRA, 2014, p. 153). A ideia de arena é aqui entendida como um espaço que, longe de ser livre de tensão, é disputado permanentemente pelas pessoas, dispostas a engajarem-se em prol do compartilhamento de seus respectivos pontos de vista, nem sempre convergentes.

Com base no panorama acima exposto, o presente artigo tem como objetivo investigar o ciberativismo de mulheres na rede social, focalizando os esforços reflexivos em torno do movimento \#ELENÃO, que envolveu a participação de mais de 2 milhões de internautas de todos os cantos do Brasil em setembro de 2018 em questionamento à campanha política do presidenciável Jair Bolsonaro. Neste contexto, houve o crescimento do protagonismo político orquestrado por mulheres no dia 13 de setembro de $2018^{5}$ com a hashtag \#ELENÃO, em referência ao candidato à presidência supracitado. Esse movimento ciberativista, organizado através das redes sociais, somente foi possível em função da infraestrutura técnica da rede mundial de computadores,

\footnotetext{
${ }^{4}$ Fonte: https://bit.ly/2NhrJca. Acesso em 22 set. 2018.

5 Para maiores informações acesse https://bit.ly/2px1u7X. Acesso em 22 set. 2018.
} 
possibilitando que o \#ELENÃO alcançasse o primeiro lugar dos Trending Topics ${ }^{6}$ do Twitter no Brasil e estivesse entre as $\operatorname{tags}^{7}$ mais utilizadas do mundo. O ativismo na rede foi intensificado com a invasão por hackers ao grupo "Mulheres Unidas Contra Bolsonaro" no Facebook. Por causa da indignação, o crime fez viralizar ${ }^{8}$ uma série de hashtags, além de \#MulheresContraOBolsonaro, \#ELENÃO e \#ELENUNCA. O grupo, que em setembro de 2018 alcançou mais de 2 milhões de integrantes, virou um fenômeno nas redes sociais e começou a sofrer tentativas de invasão quando o perfil de uma delas foi invadido e seus dados pessoais foram expostos publicamente.

Para melhor compreender os fenômenos analisados, organizamos o presente texto em quatro seções. $\mathrm{Na}$ primeira realizamos breves considerações sobre a ciberpesquisa-formação multirreferencial com os cotidianos, a abordagem teórico-metodológica adotada na realização deste estudo. Em seguida discutimos sobre o ciberativismo e o uso de hashtags para potencializar esta difusão, já trazendo como exemplos movimentos criados por mulheres e que foram ganhando cada vez mais visibilidade para além do contexto digital. Em seguida, na terceira seção, focalizamos especificamente o movimento \#ELENÃO, criado no fervor do contexto das eleições de 2018, quando o presidenciável Jair Bolsonaro, recém eleito no Brasil, realizou uma campanha que produziu uma série de falas que além de subalternizar as mulheres, desconsideram e tornam motivo de deboche as lutas e conquistas de movimentos feministas, além de ataques à comunidade LGBTQ ${ }^{9}$. Por fim, concluímos discutindo a importância destes movimentos digitais, que agregam públicos diversos que encontram na rede vez e voz para expressarem-se.

\section{CIBERPESQUISA-FORMAÇÃO MULTIRREFERENCIAL COM OS COTIDIANOS: CONSIDERAÇÕES TEÓRICO-METODOLÓGICAS}

No que se refere à opção teórica-metodológica da pesquisa, formulamos duas questões importantes que nos inspiraram teórico e metodologicamente a realizar esta pesquisa. Nossas questões são: a) investigar quais os diferentes usos as/os usuárias/os fazem das redes sociais em seu contexto de atuação política e b) mapear as experiências e itinerâncias desses sujeitos nos movimentos ciberativistas praticados nos espaçostempos ${ }^{10}$ da cibercultura. A partir dessas questões entendemos que a pesquisa no campo das ciências humanas e sociais também é uma pesquisa sobre nós mesmos e que a pesquisa em Educação, particularmente, só terá sentido se nos conduzir a conhecer as redes que estão presentes em nossas relações, na política, na economia e em todos os contextos da vida humana. Buscamos revelar neste estudo como as práticas dos sujeitos são

\footnotetext{
6 Treding Topics ou TT's são uma lista em tempo real das palavras mais postadas no Twitter em todo o mundo. São válidos para essa lista as tagtemas e nomes próprios. A lista é exclusiva para usuários do Twitter, ou seja, você deve estar logado para ter acesso aos Treding Topics. Disponível em https://bit.ly/2Nxpw1k. Acesso em 22 set. 2018.

7 Tags são estruturas de linguagem de marcação que contêm instruções.

8 Viralizar refere-se a um termo muito utilizado hoje em dia para descrever a popularização de postagens compartilhadas na internet por um número significativo de usuárias/os.

${ }^{9}$ Não é de nosso foco neste artigo realizar uma análise dos discursos proferidos pelo candidato, embora estejam cada vez mais difundindo-se nas diferentes redes sociais. Se por um lado esses discursos venham a ferir a existência das chamadas minorias sociais, por outro lado estão convidando sujeitos de todos os cantos do Brasil a realizarem movimentos de resistência pelas redes.

10 Adotamos o uso dos termos espacostempos, dentrofora, entre outros, escritos de forma diferenciada, pois nos inspiramos no referencial teórico de Alves (2008) sobre as pesquisas nos/dos/com os cotidianos. De acordo com Oliveira, Alves (2008, p. 11), “[...] a junção de termos e a sua inversão, em alguns casos, quanto ao modo como são 'normalmente' enunciados, nos pareceu, há algum tempo, a forma de mostrar os limites para as pesquisas nos/dos/com os cotidianos, do modo dicotomizado criado pela ciência moderna para analisar a sociedade".
} 
constituídas a partir das experiências pessoais mediadas pelas redes de conhecimento também via cotidiano-ciberespaço.

A partir dessas questões, nos apropriamos da abordagem teórico-metodológica da ciberpesquisa-formação multirreferencial com os cotidianos (SANTOS, 2005; ARDOINO, 1998; MACEDO, 2010; ALVES, 2010), por reconhecermos a importância de o objeto de pesquisa ser lido "[...] sob diferentes pontos de vistas, que implicam tanto visões específicas quanto linguagens apropriadas às descrições exigidas, em função de sistemas de referenciais distintos, considerados, reconhecidos explicitamente como não redutíveis uns aos outros" (ARDOINO, 1998, p. 24). Em outras palavras, a multirreferencialidade busca esforços reflexivos em prol da realização de críticas às formas heterogêneas de compreender e analisar os fenômenos sociais contemporâneos.

Com essa abordagem, compreendemos a importância de nossa implicação ética com as/os participantes do estudo, bem como com a forma com a qual produzimos conhecimento através de uma análise interpretativa sobre o mundo. A escolha dela no contexto desta pesquisa se deu por ser a multirreferencialidade uma abordagem epistemológica que procura romper com os modelos cartesianos das pesquisas em ciências humanas e sociais. De um lado, consideramos Ardoino (1998, 2003), que assume a hipótese da complexidade e da realidade a respeito da qual nos questionamos, de outro, somamos com as contribuições de Morin (2003) a complexidade do método. A discussão da abordagem multirreferencial vem no contraponto dos pressupostos teóricos positivistas, tão sedimentados no campo educacional. Segundo Ardoino (1998), o surgimento dessa abordagem está ligado ao reconhecimento da complexidade e da heterogeneidade inerentes às práticas educativas, interessando tanto à/ao psicóloga/o, quanto à/ao economista, à/ao socióloga/o, à/ao filósofa/o, ao/à historiador/a, à/ao pedagoga/o, à/ao internauta, sempre na perspectiva de uma pluralidade de olhares e linguagens, reconhecida como necessária à compreensão dos fenômenos complexos.

Ainda de acordo com Ardoino (1998), é preciso o reconhecimento de uma heterogeneidade própria do campo das ciências humanas e sociais, visto que estas se caracterizam por uma coexistência temporal de várias perspectivas teóricas, abordagens e paradigmas, diferentemente das ciências naturais que registram um contínuo processo de sucessão de teorias organizadas hierarquicamente. O fato de aproximarmos perspectivas teóricas marcadas pela heterogeneidade, como nos apresenta a abordagem multirreferencial, nos permite mergulhar em um campo de tensão, a partir do qual podemos vislumbrar novas perspectivas epistemológicas para a compreensão dos fenômenos humanos.

Freire (2001, p. 43) afirma que "[...] na formação permanente dos professores, o momento fundamental é o da reflexão crítica sobre a prática". Compreendemos que, tanto na nossa imersão no campo, como nas nossas narrativas, "[...] é preciso que, pelo contrário, desde o começo do processo, vá ficando cada vez mais claro que, embora diferentes entre si, quem forma se forma e re-forma ao formar e quem é formado forma-se e forma ao ser formado" (FREIRE, 2001, p. 25). Caminhamos na mesma linha de pensamento de Freire, pois, na medida em que refletimos sobre as escolhas que fazemos, os espaçostempos da pesquisa vão se tornando um trabalho colaborativo produzido através de intensas trocas. Essa perspectiva de que se pesquisa e se forma no ato de pesquisar nos aproxima da ideia de aprender na interação, em que os saberes emergem das trocas, da colaboração e do compartilhamento. Dessa forma, na pesquisa-formação multirreferencial buscamos refletir sobre como agir e criar coletivamente uma prática educativa que questionasse, valorizasse e compreendesse os processos vividos nas redes sociais que, para nós, são redes educativas (ALVES, 2010).

Para acompanharmos o movimento ciberativista feminino nas redes sociais, selecionamos e analisamos algumas das principais postagens de diferentes redes sociais da internet que 
viralizaram em 2018 durante a campanha do presidenciável Jair Bolsonaro. Para isso, nos inspiramos no paradigma indiciário de Ginzburg (1989, p. 177) para quem “[...] a realidade é complexa e opaca, mas existem zonas privilegiadas - sinais, indícios - que permitem decifrá-la que permitem buscar interconexões e efetuar tentativas de compreensão da totalidade". Acreditamos que a realidade cotidiana não é transparente, não fala por si só, mas encontramos nela rastros, memórias, que nos dão sinais e indícios que possibilitam traduzir e interpretar tal opacidade. No digital, deixamos nossos rastros marcados nas maneiras como nos comunicamos, nas diversas formas de linguagens que utilizamos. Essas linguagens que imprimem nossas marcas são os indícios que deixamos para descrever e criar o mundo que nos cerca, para interagir com os membros do grupo. Desse modo, por exemplo, os membros de uma determinada comunidade se reconhecem pela linguagem, pelos saberes compartilhados, pelas ideias de pertencimento.

Assim como a página Mulheres Unidas Contra Bolsonaro no Facebook, nosso foco de análise no presente texto, outras foram sendo criadas como seus desdobramentos evidenciando o protagonismo das mulheres na rede no combate às diferentes injustiças sociais. Cabe destacar que o grupo, criado em 15 de setembro de 2018, teve seu nome modificado quando o candidato ao qual se opunham foi eleito presidente. O grupo então passou a se chamar Mulheres Unidas na Resistência na Luta Contra o Fascismo, alteração feita em 29 de outubro de 2018, ou seja, no dia do resultado das eleições. $\mathrm{Na}$ ocasião da escrita deste texto, o grupo contava com cerca de $40.450^{11}$ membros, todas mulheres, pois uma das regras do ambiente virtual é a proibição da entrada de homens (são banidos assim que detectados).

Diversos temas estão veiculados nas imagens-dizeres dessas postagens, nos convidando a rediscutir aspectos da vida cotidiana que merecem destaque porque dizem respeito a forma como essas questões sociais, de natureza preconceituosa e discriminatória, ainda predominam no cenário social brasileiro. Esses temas incluem o assédio, a legalização do aborto, a igualdade salarial das mulheres em relação a questões trabalhistas, além de novas formas de viver e de ser mulher que questionam o processo de subalternização feminina construída historicamente, na tentativa de deslocar seu papel social das margens em prol da defesa de seu protagonismo nas decisões políticas de nosso tempo.

\section{ATIVISMO COLETIVO EM REDE ATRAVÉS DE HASHTAG: MOVIMENTOS DE (RE)EXISTÊNCIA}

A conexão, um dos princípios da cibercultura, nos permite cocriar em rede, entrar em conexão com outras pessoas, produzir sentidos, trocar informações, circular, distribuir informações, saberes, conhecimento. A internet configura-se como lugar de conexão e compartilhamento. Vemos crescer a passos largos as formas de produção e de circulação de informação como processos colaborativos e em rede. Para Lemos e Lévy (2010, p. 46), forma-se uma nova economia política, em que a "produção é liberação da emissão e consumo é conexão, circulação, distribuição". O contexto político contemporâneo vem evidenciando a espontaneidade dos movimentos organizados através das dinâmicas ciberculturais, "[...] cujos efeitos antes não eram possíveis em uma sociedade caracterizada pela mídia de massa. As próprias práticas de ciberativismo comprovam a força dos meios digitais para a articulação, mobilização e ações políticas" (PRIMO, 2013, p. 17).

\footnotetext{
${ }^{11}$ Fonte: https://www.Facebook.com/groups/254700008567799/about/. Acesso em 10 de jan. 2019.
} 
Diversos trabalhos analíticos já se dispuseram a investigar os processos comunicacionais digitais mediados pelas redes sociais, incluindo a construção de estratégias de resistência no Facebook através da crítica às normas regulatórias de gênero por grupos de sujeitos não-heterossexuais (COUTO JUNIOR; OSWALD, 2017; COUTO JUNIOR; BRITO; POCAHY; AMARO, 2019), as manifestações de 2013 no Brasil desencadeadas pelo descontentamento político da época, incluindo o aumento das passagens dos ônibus no Rio de Janeiro (CASTELLS, 2013), os usos da internet por grupos constituídos por pessoas fascistas do Brasil e da Argentina (MAYNARD, 2014), além de estudo que explora o surgimento no Facebook do movimento antipetista e antiesquerdista (SANTOS, 2014), para citar alguns.

No que tange aos movimentos de ativismo feminista nas redes, vale estabelecer como um marco de grande relevância o movimento \#MeuAmigoSecreto, que ganhou difusão nas redes em 2015. Esse movimento organizado através da internet colocou em debate experiências de mulheres que, cotidianamente, vinham se sentindo oprimidas por relações machistas e de constrangimentos diversos (morais, psicológicos e físicos, para citar alguns), fortalecendo a trocas entre/com elas através do intercâmbio de histórias que evidenciavam situações de assédio pelas quais vinham passando. Esse sentimento de empatia fortaleceu os grupos e o movimento, sendo até hoje é reconhecido como um marco importante acerca do ativismo feminino nas redes sociais.

A hashtag \#MeuAmigoSecreto, conforme indicam as organizadoras do Não me Kablo ${ }^{12}$, não surgiu de uma campanha planejada, mas de uma construção coletiva, como temos visto ocorrer em muitos destes movimentos que se iniciam em redes sociais. Ainda segundo as administradoras da página, a "[...] adesão maciça de diferentes mulheres possibilitou que outras tivessem coragem também para contar os próprios casos" (NÃO ME KAHLO, 2016, p. 15). Dessa forma, a hashtag se transformou em algo muito maior do que haviam imaginado. Reconhecemos aqui a esse movimento como forma de denúncia, como forma de compartilhar o peso que carregavam durante anos e encontrando em outras vozes análogas com as quais pudessem partilhar suas dores e como forma de conectar trajetórias e fortalecer vínculos criados a partir de dores.

As acusações se davam por meio de indiretas que faziam as leitoras se identificarem mais com as narrativas, mas sem identificar quem eram os alvos das acusações. Diferentemente do que presenciamos com o movimento \#ELENÃO, o alvo tem nome, sobrenome, partido e propostas que no entendimento dos grupos de ciberativistas que o denunciam, não as representa enquanto chefe de uma nação, e que precisa ser combatido tanto nas redes como nas ruas, pelos movimentos que as mesmas organizam.

O ponto em comum reside na força feminina que se destaca e a convocação para que, para além das suas diferenças, possam caminhar juntas frente a uma ameaça comum. Exemplo disto se evidencia na postagem abaixo retirada da rede social Instagram, no qual observamos mulheres com as mais distintas características, seguindo de mãos dadas. Os dizeres que acompanham a imagem também nos dizem muito:

Eu tenho tanta coisa pra falar, mas o desgaste que me dá só de pensar em discutir com essa galera que apoia o fascismo, militarismo, dentre outras coisas relacionadas ao dito cujo. Então só queria exercer a liberdade de expressão que me resta ainda nessa democracia fragilizada que vivemos e dizer que \#elenão \#elenunca.

${ }^{12}$ Fonte: https://www.Facebook.com/NaoKahlo/. Acesso em 2 out. 2018. 
Figura 1: Eu não luto sozinha

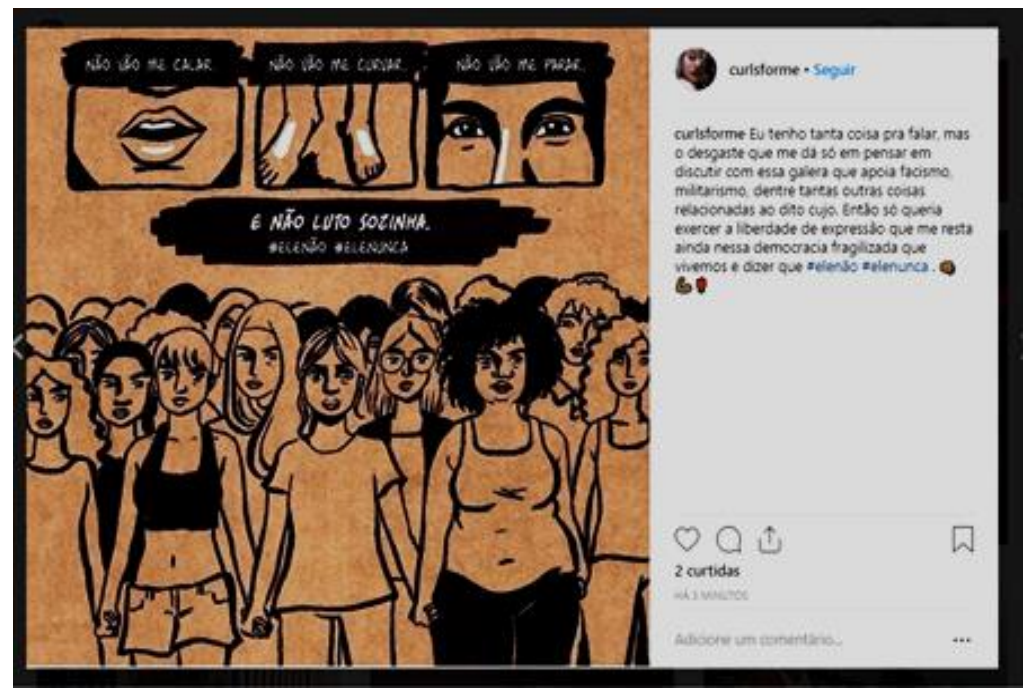

Fonte: https://bit.ly/2ycVhmy

É neste contexto de dinâmicas e processos culturais em que os espaçostempos da cidade são estruturados por tecnologias digitais em rede que nos inspiramos na análise dos novos fenômenos sociotécnicos que emergem com os usos e com a imersão nas diversas redes educativas, e no caso deste artigo, na rede social Facebook. Para Lemos e Lévy (2010), as redes sociais possuem um papel relevante como fonte de interpretação da realidade, modificando e expandindo áreas de experiência individual, intervindo na formação da opinião pública e contribuindo para a definição de identidades individuais e coletivas. Dito isso, não há como desconsiderar a importância do Facebook enquanto um espaço de ambiências formativas para além da mera circulação de informações, na medida em vem se caracterizando como um terreno fértil na promoção de debates durante as campanhas políticas.

Castells (2013, p. 184), ao discutir sobre a importância das redes sociais nas mobilizações políticas que resultaram em diversas manifestações mundo afora, afirma que "[...] as mídias e redes sociais são instrumentos de conversação e de trocas abertas de informações. Elas servem para fazer circular aquilo que os governos tentam esconder, ou aquilo que a grande mídia não informa por interesses particulares". Para o autor, essas redes expressam formas de relação sociotécnica e inauguram o advento de uma dimensão ciberativista. Para Silveira (2010), essa dimensão é o que ele denomina de ciberativismo, ou seja, um conjunto de práticas em defesa de causas políticas, socioambientais, sociotecnológicas e culturais realizadas principalmente na internet. Ainda de acordo com Silveira (2010), o ciberativismo influencia decisivamente grande parte da dinâmica e das definições sobre os principais protocolos de comunicação utilizados na internet.

Assim, ciberativismo é um conjunto de táticas coletivas que manifestam a busca por transformações sociais a partir de ações de cooperação (ZAGO, BATISTA, 2011). O ciberativista se apropria das tecnologias digitais, configurando o ciberespaço como uma nova esfera interconectada (SILVEIRA, 2010), que também afeta e traz implicações sociais para a educação na medida em que tais eventos pautam/agendam ações de professoras/es e alunas/os. O cenário de mudança das mídias pós-massivas, entre outros aspectos, reconfigura o processo comunicacional desde a criação até a divulgação das mensagens midiáticas, bem como as mudanças nos perfis profissionais e nos processos de produção de conhecimento (SANTAELLA, 2010). 
DOI: https://doi.org/10.12957/teias.2020.48628

QUANDO ELAS DIZEM \#ELENÃO: FORJANDO COLETIVOS NA/EM REDE CONTRA O FASCISMO

Numa manhã, eu acordei e ecoava ele não, ele não, ele não!!!
Numa manhã, eu acordei e lutei contra um opressor.
Somos mulheres, a resistência. Por um Brasil sem fascismo e
sem horror.
Vamos à luta para derrotar o ódio e pregar o amor. Bis

O trecho acima, retirado do grupo Professoras e professores unidos contra o fascismo! ${ }^{13}$, traz questões importantes sobre os fatores emergentes que se constituem em profundas mudanças pelas quais as subjetividades, a cultura, a política e o comportamento das pessoas vêm passando. Para Gabriel (2012, p. 51), “[...] somos on e off ao mesmo tempo, simbioticamente formando um ser maior que o nosso corpo e o nosso cérebro biológico, nos expandindo para todo tipo de dispositivo e abrangendo outras mentes e corpos". Compreender o que fazemos com as redes sociais é fundamental. Entretanto, é importante também compreendermos de quais formas a relação que vimos estabelecendo com outras/os internautas via redes sociais digitais estão alterando nossas subjetividades, nossos modos de receber e compartilhar informações, nossa memória, nossos anseios e desejos, o modo como produzimos conhecimento, percebemos e representamos o mundo.

Grande parte das gerações que estão nascendo hoje nunca souberam o que é viver em um contexto de regime ditatorial. Estamos nos referindo aqui a crianças e jovens que chegaram ao mundo com a já promulgada Constituição Cidadã de 1988, que assegura seus direitos e deveres. Esses sujeitos tampouco sabem o que é ter sua liberdade de expressão cerceada, o direito de ir e vir impedidos e viver sob o jugo de um controle de suas ações e reações, que se não em consonância com um dado governo estabelecido, podem sofrer sanções e punições que, historicamente, atentaram contra vidas. Ainda que estas gerações não tenham vivido fascismos e ditaduras, muitos jovens têm se mobilizado para combater a ascensão de grupos sociais ultraconservadores que pregam este retorno, verdadeiro retrocesso em relação a tudo o que historicamente já conquistamos durante o período democrático pós-1985.

Temos percebido o uso cada vez mais corriqueiro do termo fascista, referindo-se a um dos candidatos à presidência. O estudo de Falcon (2008) nos permite uma compreensão mais precisa do que estamos tratando. $\mathrm{O}$ autor aponta que a palavra fascismo se origina do italiano fascio, que significa feixe, um símbolo de autoridade da antiga Roma. Associa-se ao movimento político datado dos anos de 1919, em Milão, por Benito Mussolini. Deste modo, a palavra fascismo envolve um movimento político e ideológico que foi liderado por Mussolini, a partir de 1922, regime que foi se organizando na Itália para a construção de um Estado Fascista. Aos poucos, várias ramificações deste movimento foram surgindo, mas todas centradas na figura de um suposto líder, afinando-se com partidos nacionalistas de extrema-direita. Em comum também há a ideia de serem antiliberais, antidemocráticos, antibolchevistas.

O que Mussolini e seus adeptos concordavam era com a existência de uma ordem totalitária, capaz de aglutinar todos os cidadãos e grupos sociais em torno do partido fascista, que naquele contexto era o italiano, mas poderiam ser outros que foram surgindo posteriormente. Investiam no militarismo, na obsessão com a segurança nacional, desprezo pelos direitos humanos e por intelectuais e artistas, controle e censura da mídia, e dentre outros, o uso da religião como forma

13 Grupo disponível em https://bit.ly/2Q5kOEM. Acesso em 25 set. 2018. 
de manipulação (HOBSBAWM, 2006). Cabe reiterar ainda que não podemos pensar o fascismo no singular, pois esse regime totalitário nos trouxe possibilidades analíticas de perceber a complexidade de suas ressignificações na conjuntura social ao longo da história (FALCON, 2008). Não obstante, é motivo de nosso espanto o quanto propostas muito semelhantes às de governos que vigoraram no começo do século XX ainda encontrem ecos nas falas de candidatos à presidência em 2018 no Brasil, cujos argumentos políticos carregam vestígios de momentos tenebrosos de nossa história, como o próprio período ditatorial.

Observando as dinâmicas de interação nas redes sociais, percebemos que diversos grupos e pessoas escolhem o Facebook e o Twitter para se encontrar, trocar ideias e manifestar opiniões sobre determinado assunto ou situação política. No ciberespaço, questões de natureza local ganham alcance planetário, o que possibilita grandes mobilizações globais. Para Castells (2003, p. 7), "[...] a internet é o tecido das nossas vidas", porque estamos, a todo instante, imersos em uma virtualidade não presencial, isto é, estamos em rede por diversos e distintos aparatos tecnológicos graças à evolução da $W e b 2.0$, forjando dispositivos formativos, coletivos, colaborativos e em rede.

As manifestações de 2013, analisadas por autores como Castells (2013) e Maricato et al (2013), fizeram ressurgir os protestos de rua que há muito não se apresentavam tão expressivos no país. Naquele momento as pautas eram dispersas, havia discursos que propunham romper com o status de representação, ao mesmo tempo em que impeliam partidos e demais organizações políticas a questionar a si mesmos. Com a deposição da presidenta Dilma Rousseff e a proposta de Reforma da Previdência, outras manifestações ganharam expressão nas ruas e nas redes. Algumas das pautas apresentadas em 2013 continuam ecoando em 2018, de forma mais intensa e polarizada, como é o caso da rejeição de partidos e organizações políticas tradicionais.

Feitas as considerações supracitadas, como indagam Abreu, Dorneles e Gonçalves (2018) ${ }^{14}$, o que isso tem a ver com o grupo de Facebook Mulheres Unidas contra Bolsonaro? Algumas afirmações foram no sentido de apontar que são apenas movimentos feministas de pouca repercussão ou temendo perder os privilégios da esquerda. Contudo, do que pudemos extrair de nossas análises da página e do movimento é que essa ação individual, que se afirma democrática e suprapartidária de amiga convida amiga, é bem própria das construções dos coletivos feministas, no sentido de acolhida e compartilhamento. A imagem de perfil que ganha máscara contra o fascismo começou de modo ainda tímido em junho de 2018 e, em quatro dias, virou uma explosão de luta e expressão na rede.

Figura 2: Descrição da página Mulheres Unidas contra Bolsonaro

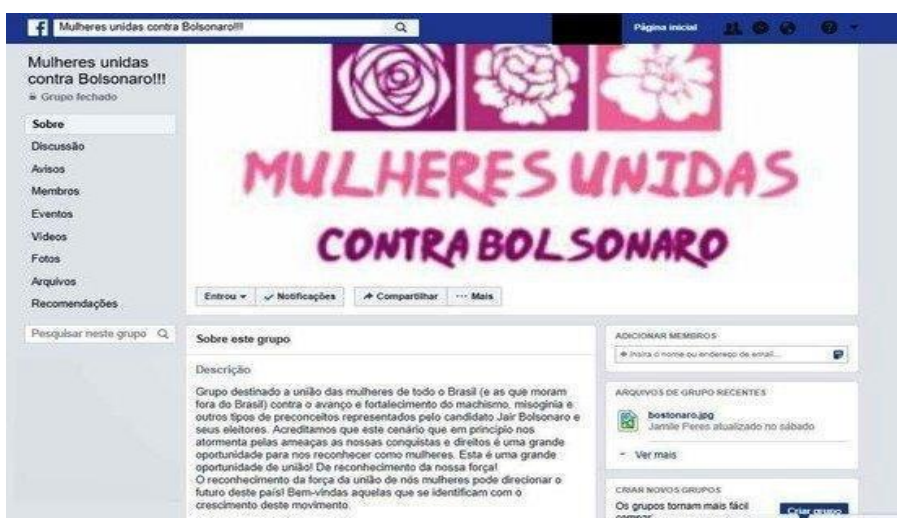

Fonte: $\underline{\text { https://www.Facebook.com/groups/499414607198716/ }}$

${ }^{14}$ Fonte: https://bit.ly/2NhrJca. Acesso em 2 out. 2018. 
De acordo com a descrição da página no Facebook Mulheres Unidas contra Bolsonaro, o grupo nasceu com a intenção de agregar os discursos de eleitoras indignadas com os posicionamentos do presidenciável em relação aos direitos das mulheres, uma das criadoras. De acordo com ela, "Percebia nas minhas próprias redes muitas amigas comentando e criticando essas posturas, então decidimos unir todas essas mulheres e criar um fato político para mostrar que grande parte da população não é favorável a essa candidatura" ${ }^{15}$. Isso aconteceu na quinta-feira, 30 de agosto. $\mathrm{O}$ grupo, exclusivamente feminino, 24 horas depois já chegava a 600.000 participantes. O rápido crescimento se desdobrou na convocatória de uma manifestação contra o candidato, em 29 de setembro, em diversos Estados do Brasil.

Algumas postagens foram se apresentando como bem emblemáticas, pois definiam regras do grupo, que por ser secreto, somente recebia inclusões de novas membras mediante análise de perfis das administradoras.

Postagem: 20 de setembro de 2018

NOTA OFICIAL DO GRUPO MULHERES UNIDAS CONTRA BOLSONARO - ASCOM

1 - GRUPO SECRETO: O Facebook no momento só permite a opção de secreto para o nosso grupo, assim que liberar trocaremos para fechado.

2 - NOTIFICAÇÕES: Por ele estar secreto as notificações não aparecem no feed de notícias de vocês. O grupo NÃO ESTÁ PARADO, apenas é preciso clicar e entrar nele para ver as postagens.

3 - POSTS: Estamos aceitando posts, mas muitos são repetidos ou propagandas políticas. Confiram na página se a postagem que vocês vão enviar já não foi postada por outra membra, assim novos posts serão aprovados mais rápido. NÃO ENVIEM PROPAGANDAS POLÍTICAS, ENQUETES DE CANDIDATOS OU GRÁFICOS.

4 - PLURIPARTIDÁRIO: O grupo $\mathrm{n}$ tem partido, mas as membras podem ter suas opiniões. FOQUEM NO INOMINÁVEL E VAMOS PARAR COM A BRIGA CIRO X HADDAD

5 - POSTAGENS NOVAS: As postagens novas muitas vezes não aparecem para vocês porque o pessoal comenta nas velhas e elas voltam para o topo toda vez que alguém comenta.

6 - NOVAS MEMBRAS: Estamos adicionando, mas a demanda é muito grande, tenham paciência e não nos mandem os nomes de quem vocês adicionaram. Temos uma fila e iremos segui-la, é o justo.

7 - ADMS: Tenham um pouco mais de empatia e paciência, estamos dando o nosso melhor, estamos em poucas por ordem do Facebook, aos poucos iremos aumentar.

8 - FOCO NO POST: Por favor, comentem no post apenas coisas relativas a ele e evitem brigas partidárias. Se alguém fez uma propaganda política, não retribua, apenas denuncie e apagaremos.

9 - POST FIXO DOS CANDIDATOS: Eles retornarão no início da tarde, POR FAVORZINHOOO, NÃO COMENTEM NO POST DO CANDIDATO QUE NÃO É O SEU. RESPEITE A OPINIÃO DE TODAS. 10 - Leiam as regras do grupo para que possamos funcionar da melhor forma possível.

11 - Não adicionem HOMENS

${ }^{15}$ Fonte: https://bit.ly/2p4ggD6. Acesso em 2 out. 2018. 
DOI: https://doi.org/10.12957/teias.2020.48628

12 - Entrem no instagram unidascontrabolso e no twitter@contra_unidas do grupo e vamos dominar lá também! E postem várias vezes ao dia nossa \# \#EleNao \#MUCBvive \#MulheresUnidasContraBolsonaro\#Filhodocoisocoi sinhoé \#nãosomosdesajustadas.

Figura 3: Foto de capa da página Mulheres Unidas contra Bolsonaro

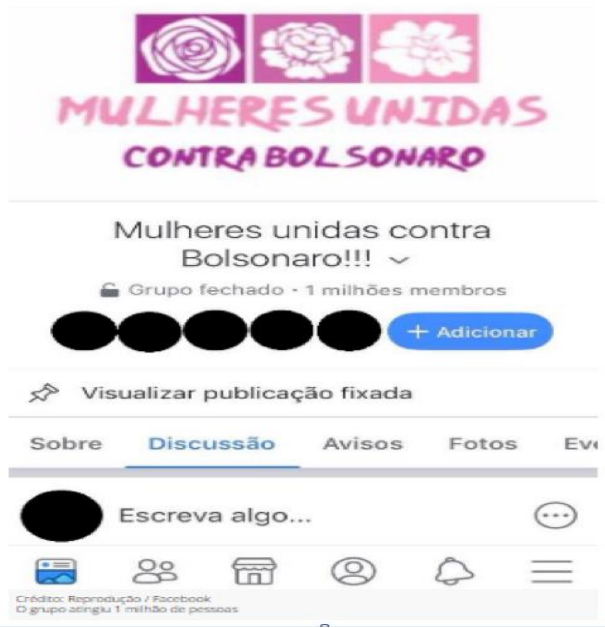

Fonte: https://www.Facebook.com/groups/499414607198716/

Segundo as regras das moderadoras, o grupo é destinado apenas para mulheres cisgênero ${ }^{16}$ ou transexuais, as discussões devem ocorrer de forma respeitosa, e não são permitidos discursos de ódio, enquetes sobre intenção de votos durante a campanha eleitoral de 2018 e a exposição de publicações feitas dentro da comunidade. De acordo com uma das administradoras do grupo Mulheres Unidas contra Bolsonaro ${ }^{17}$, o objetivo da iniciativa não é atacar Jair Bolsonaro, mas sim, lutar contra o fascismo e o retrocesso que ele representa. A ideia do grupo surgiu como forma de juntar as mulheres em luta por seus direitos. No entanto, como se tornou algo muito maior, os planos das integrantes agora incluem organizar manifestações em cidades pelo país, de forma a manter essa rede de apoio.

Apesar do filtro criado para a entrada de membros no grupo, este não evitou a invasão de perfis fakes que entravam na página fazendo comentários incitando o ódio e apoiando o candidato que o grupo se opunha. Os invasores chegaram a estipular um prazo para o grupo ser extinto. $\mathrm{O}$ ataque virtual afetou as contas das administradoras do grupo, que tiveram suas contas do Facebook e Whats $A p p$ invadidas. Antes das ameaças diretas, moderadoras e administradoras haviam recebido ameaças em suas contas no Whats $A p p$. Os invasores exigiram que o grupo fosse extinto até às $24 \mathrm{~h}$ de 14 de setembro de 2018 e tentaram intimidar as responsáveis pelo grupo ameaçando divulgar seus dados pessoais como Cadastro de Pessoa Física (CPF), Registro Geral (RG), Título de eleitor, nome da mãe, entre outros dados pessoais ${ }^{18}$. O grupo foi hackeado após diversas postagens ofensivas, saiu do ar, teve de trocar de nome e somente algum tempo depois voltou a ficar ativo ${ }^{19}$.

\footnotetext{
${ }^{16}$ Cisgênero refere-se às pessoas que se identificam com o gênero que lhes foi atribuído no nascimento.

17 Por se tratar de um grupo que no momento da escrita deste texto se apresenta como secreto, não identificaremos a moderadora por entender que manter seu anonimato implica questões éticas que pretendemos garantir.

${ }^{18}$ Fonte: https://bit.ly/2xeAU89. Acesso em 17 set. 2018.

${ }^{19}$ Fonte: https://bit.ly/2xeAU89. Acesso em 28 set. 2018.
} 
Em tempos de intensa proliferação de discursos de ódio, quando nem sempre todas as mortes são passíveis de serem lamentadas (BUTLER, 2011), essa rede de apoio solidária no Facebook constitui-se enquanto importante estratégia de (re)existência. Nessa linha de pensamento, vale lembrar aqui que, de acordo com Rich (2010, p. 21), “[...] tanto a coerção como a compulsão estão entre as condições nas quais as mulheres [e outros tantos sujeitos] têm aprendido a reconhecer sua própria força”. Dessa forma, defendemos que a pauta do movimento feminista seja amplamente difundida em nossa sociedade, porque ela nos favorece pensar a forma com a qual as relações de poder se instituem, principalmente aquelas que buscam reforçar as hierarquias de gênero.

A repercussão do movimento feminista sobre a sociedade é imensurável, posto que vem proporcionando alterações significativas na base da sociedade e nos valores consolidados, levantando bandeiras como a liberdade sexual, o questionamento da família tradicional e dos papéis na sociedade, a afirmação da própria personalidade e a desconstrução de uma cultura predominantemente machista. Isso decorre de uma ação em diversas frentes, como a participação em políticas sociais, multiplicação dos espaços de atuação das mulheres. Para isso, defendemos que as tecnologias digitais em rede sejam usadas "[...] para construir estratégias de interação com o mundo físico e social, que sejam promotoras de certo modo de ver as coisas, interpretando e recriando o mundo de muitas e diferentes maneiras" (JOBIM E SOUZA, 2002, p. 77).

O movimento feminista, ao encontrar na rede espaço para se ampliar/fortalecer, vem questionar "[...] a exclusão social das mulheres do mundo público, assim como o silenciamento e a desqualificação de seus temas e questões" (RAGO, 2001, p. 65). Conforme reitera Rago (2001, p. 65), esse movimento historicamente "[...] lutou e luta para que as mulheres se reconheçam como sujeitos políticos, cidadãs com deveres e direitos a serem reconhecidos e criados". Precisamos do feminismo para mostrar que as marcas de gênero têm implicação social (SILVA, 2010) diretamente ligadas à manutenção das ideologias do regime heterocentrado, que reforça a centralidade do homem branco heterossexual cristão no ocidente e relega às margens sociais as mulheres e outros sujeitos que integram as chamadas minorias (PRECIADO, 2014). Precisamos do feminismo para (re)pensar as estratégias de luta e resistência a serem adotadas em resposta aos pensamentos machistas que (ainda) reinam supremos em nossa sociedade (BENTO, 2011).

\section{AS PESQUISAS EM EDUCAÇÃO E OS MOVIMENTOS CIBERATIVISTAS DE (RE)EXISTÊNCIA NAS REDES SOCIAIS: BREVES CONSIDERAÇÕES FINAIS}

As dinâmicas ciberculturais contemporâneas nos convidam a (re)pensar a relação dos sujeitos com a cidade e com as tecnologias digitais, além da constituição dos movimentos ciberativistas de (re)existência nos diferentes espaçostempos da vida cotidiana. As interações sociais vêm se transformando a partir dessas novas práticas estabelecidas e conectadas pela comunicação na/em rede. O protagonismo feminino evidenciado nas redes durante a campanha eleitoral de 2018 no Brasil, conforme apresentado e discutido no texto, se intensificou a partir do momento em que diversos dispositivos formativos foram acionados (páginas e grupos secretos de Facebook e grupos de WhatsApp, para citar alguns) em vistas de colocar em prática movimentos que pudessem expressar a insatisfação de mulheres contra as intensas ondas de violência enfrentadas durante aquele período.

Além de trocarem informações, também se organizavam em atos que se constituíram em uma verdadeira rede de solidariedade e empoderamento, imprescindíveis para que o movimento ganhasse tamanha força e expressividade dentrofora da rede. Como educadoras/es, cabe refletirmos 
sobre o quanto esses e outros movimentos ciberativistas são capazes de nos ensinar sobre as tantas possibilidades de (re)existência possíveis numa época nitidamente marcada pela mediação das redes sociais da internet.

No que tange à resistência feminista, reconhecemos que Direitos foram adquiridos, mas estes não podem nos perder a vigilância frente a regressões possíveis. Daí a importância de conhecermos e valorizarmos histórias e trajetórias de mulheres que nos auxiliaram a caminhar em direção a um mundo mais igualitário, no que se refere a relações entre homens e mulheres (BARCELLA, LOPES, 2018). Mulheres que já se levantavam para se opor às injustiças e que hoje, com a potência que as redes sociais possuem, nos inspiram a seguir resistindo.

Ao discutirmos neste texto sobre os movimentos ciberativistas de (re)existência, nos questionamos: o que podemos aprender com o protagonismo político de mulheres nas redes sociais? Nos parece útil o planejamento de táticas para reinventar outros modos de (re)existir. Esses movimentos nos inspiram para o debate necessário sobre como uma educação antifascista nos trazem elementos reflexivos importantes para pensar as diferentes redes educativas. Para isso, temos o desafio pela frente de reconhecer a reconfiguração dos atos políticos que vêm se manifestando por meio de práticas coletivas envolvendo as múltiplas relações dos sujeitos nas redes cotidianas de conhecimentos e significações.

Nas redes sociais, podemos constatar o quanto nós, educadoras/es, somos capazes de aprender com os movimentos de (re)existências nas redes, responsáveis por forjar novas subjetividades e ampliar as possibilidades de arenas de debates, numa polifonia rizomática cujos contornos ainda principiamos por compreender a dimensão e os desdobramentos. Cabe reiterar que os desafios à compreensão dessas dinâmicas ciberculturais são indicadores de processos possíveis de (re)existência para os contextos de formação de professores na contemporaneidade.

Concordamos com Beard (2018), quando nos ajuda a ter cautela para analisar um suposto sucesso feminino e a ampliação das esferas de poder conquistadas. $O$ fato de haver todo um movimento se levantando para proclamar o \#ELENÃO nos convida a pensar sobre o quanto as mulheres já têm certa visibilidade social no tempo presente, mas isso não significa que a luta cotidiana está encerrada, longe disso. Ainda não temos concretamente uma contrapartida que seja \#ELASIM, embora o candidato ao qual os movimentos ciberativistas se opõem seja o que mais fere sua legitimidade enquanto coletivos feministas. O próprio quantitativo de mulheres engajadas já nos traz um lampejo de esperança, no sentido discutido por Freire (2011), aqui por nós sendo apropriado para expressar o quanto cremos na potência destas redes formadas e no quanto podem ir ainda mais longe. Temos então o otimismo e a esperança, no sentido de que estamos nos levantando, juntando-nos com outros grupos e não desistindo na busca da construção de novas possibilidades de (re)existência.

Como profissionais do campo da Educação atuantes em cursos de formação de professores, nosso desafio deve ser o de aprender coletivamente com esses movimentos e fomentar discussões que possam ser potentes para questionar os acontecimentos contemporâneos. Os movimentos ciberativistas de (re)existência nos permitem olhar com mais atenção para as reivindicações e demandas dos diferentes grupos sociais no Brasil. No caso do movimento \#ELENÃO, orquestrado por mulheres de todas as regiões do país, somos instigados a reconhecer o quanto o Facebook e outras redes sociais constituem-se enquanto importantes redes educativas capazes de mobilizar politicamente uma quantidade significativa de usuárias em torno de uma mesma rede de transmissão e acesso que coloca em questão temas como o machismo, misoginia, discriminação e preconceito, para citar alguns. De forma alguma esse movimento de (re)existência foi extinto em função do resultado das eleições de 2018 no Brasil, o que vemos é a atualização de sua pauta para atender as demandas do grupo na medida em que o tempo avança e outras questões 
vêm à tona no cenário político nacional, permitindo um maior engajamento de setores da população que até então não se envolviam com questões político-partidárias.

Com isto convidamos as/os leitoras/es a um breve exercício heurístico. Se nos tempos do fascismo de líderes como Mussolini na Itália, Hitler na Alemanha e Salazar em Portugal, se as mulheres dispusessem de um arsenal digital como o que temos nos tempos de hoje, dizer ele não muito provavelmente não seria apenas um pensamento ou algo que não dizia respeito. Em 2018, com a potência comunicacional do digital em rede, somos interpelados a nos engajar politicamente, manifestando descontentamentos com outras/os sujeitos geograficamente dispersas/os. Quando as mulheres vão para as redes e ruas gritar \#ELENÃO, essa prática ecoa para além do território nacional, garantindo que nossa história local seja compartilhada mundo afora, na esperança de que outras pessoas possam ouvir e participar de nossos esforços diários a fim de garantir o reconhecimento e a legitimidade de nossas existências.

\section{REFERÊNCIAS}

ALVES, Nilda. Sobre movimentos das pesquisas nos/dos/com os cotidianos. p. 39-48. In: OLIVEIRA, Inês Barbosa, ALVES, Nilda (orgs.). Pesquisa no/do cotidiano das escolas: sobre redes de saberes. Petrópolis: DP\&A, 2008.

ALVES, Nilda. A compreensão de políticas nas pesquisas com os cotidianos: para além dos processos de regulação. p. 1195-1212. Educação \& Sociedade, Campinas, v. 31, n. 113, out./dez. 2010. Disponível em https://bit.ly/2RMr6uM. Acesso em 12 out. 2018.

ARDOINO, Jacques. Abordagem multirreferencial (plural) das situações educativas e formativas. p. 24-41. In: BARBOSA, Joaquim Gonçalves (org.). Multirreferencialidade nas ciências e na educação. São Carlos: EdUFSCar, 1998.

ARDOINO, Jacques. Para uma pedagogia socialista. Brasília: Plano, 2003.

BARCELLA, Laura, LOPES, Fernanda. Lute como uma garota: 60 feministas que mudaram o mundo. São Paulo: Cultrix, 2018.

BEARD, Mary. Mulheres e poder: um manifesto. São Paulo: Planeta do Brasil, 2018.

BENTO, Berenice. Na escola se aprende que a diferença faz a diferença. p. 549-559. Revista Estudos Feministas, Florianópolis, v. 19, n. 2, maio/ago. 2011. Disponível em https://bit.ly/1VWhF9m. Acesso em 12 out. 2018.

BUTLER, Judith. Vida precária. p. 13-33. Contemporânea - Revista de Sociologia da UFSCar, São Carlos, v. 1, n. 1, jan./jun. 2011. Disponível em https://bit.ly/2zpGIgr. Acesso em 4 out. 2018.

CASTELLS, Manuel. Redes de indignação e esperança: movimentos sociais na era da internet. Tradução de Carlos Alberto Medeiros. Rio de Janeiro: Zahar, 2013.

CASTELLS, Manuel. A galáxia da Internet. Rio de Janeiro: Jorge Zahar, 2003.

COUTO JUNIOR, Dilton Ribeiro, OSWALD, Maria Luiza Magalhães Bastos. Cibercultura, juventudes e heteronormatividade: ativismo e resistência no Facebook. p. 153-174. Revista Debates, Porto Alegre, v. 11, n. 2, maio/ago. 2017. Disponível em https://bit.ly/2pquU7L. Acesso em 20 set. 2018.

COUTO JUNIOR, Dilton Ribeiro; BRITO, Leandro Teofilo de; POCAHY, Fernando; AMARO, Ivan. Jovens em estado de alerta no Facebook: diálogos tecidos em/na rede como estratégia de (re)existência à regulação das vidas precarizadas. p. 1210-1229. Práxis Educativa, Ponta Grossa, v. 14, n. 3, set./dez. 2019. Disponível em https://bit.ly/2oqpqfW. Acesso em 2 out. 2019. 
FALCON, Francisco José Calazans. Fascismo: novas e antigas ideias. p. 11-28. In: PARADA, Mauricio (org.). Fascismos: conceitos e experiências. Rio de Janeiro: Mauad X, 2008.

FREIRE, Paulo. Pedagogia da autonomia: saberes necessários à prática educativa. São Paulo: Paz e Terra, 2001.

FREIRE, Paulo. Pedagogia da esperança: um reencontro com a pedagogia do oprimido. 17. ed. São Paulo: Paz e Terra, 2011.

GABRIEL, Martha Carrer Cruz. Arte transmídia na era digital. 2012. Tese (Doutorado em Poéticas Visuais) - Escola de Comunicações e Artes, Universidade de São Paulo, São Paulo, 2012. Disponível em https://bit.ly/2ywWILZ. Acesso em 20 abr. 2014.

GINZBURG, Carlo. Mitos, emblemas e sinais: morfologia e história. São Paulo: Companhia das Letras, 1989.

HOBSBAWM, Eric. Era dos extremos: o breve século XX: 1914-1991. 22. ed. 33. reimpressão. São Paulo: Companhia das Letras, 2006.

JOBIM E SOUZA, Solange. O olho e a câmera: desafios para a educação na época da interatividade virtual. p. 75-81. Revista Advir, Rio de Janeiro, n. 15, set. 2002.

LEMOS, André, LÉVY, Pierre. O futuro da internet: em direção a uma ciberdemocracia planetária. São Paulo: Paulus, 2010.

MACEDO, Roberto Sidnei. Compreender e mediar a formação: o fundante da educação. Brasília, Distrito Federal: Líber Livro, 2010.

MACEDO, Nélia Mara Rezende, PEREIRA, Rita Marisa Ribes. Ser amigo e ter amigos no Facebook: uma análise com crianças. p. 149-166. In: PORTO, Cristiane, SANTOS, Edméa (orgs.). Facebook e educação: publicar, curtir, compartilhar. Paraíba: EdUEPB, 2014. Disponível em https://bit.ly/2wcJuWP. Acesso em 13 out. 2018.

MARICATO, Ermínia [et.al]. Cidades rebeldes: Passe Livre e as manifestações que tomaram as ruas do Brasil. São Paulo: Boitempo: Carta Maior, 2013.

MAYNARD, Dilton Cândido Santos. Intolerância ao Sul da América: estudo comparado de grupos fascistas do Brasil e da Argentina na Internet (1996-2007). p. 54-84. Revista Tempo e Argumento, Florianópolis, v. 6, n. 12, maio/ago. 2014. Disponível em https://bit.ly/2EqwZv4. Acesso em 12 out. 2018.

MORIN, Edgar. Educar na era planetária: o pensamento complexo como método de aprendizagem no erro e na incerteza humana. Tradução de Sandra Trabucco Valenzuela. São Paulo: Cortez; Brasilia, Distrito Federal: Unesco, 2003.

NÃO ME KAHLO. \#MenamigoSecreto: feminismo além das redes. 1. ed. Rio de Janeiro: Ed. Rio de Janeiro, 2016.

OLIVEIRA, Inês Barbosa, ALVES, Nilda. Contar o passado, analisar o presente e sonhar o futuro. p. 9-14. In: OLIVEIRA, Inês Barbosa, ALVES, Nilda (orgs.). Pesquisa no/ do cotidiano das escolas: sobre redes de saberes. Petrópolis: DP\&A, 2008.

PRECIADO, Paul Beatriz. Manifesto contrassexual: práticas subversivas de identidade sexual. Tradução de Maria Paula Gurgel Ribeiro. São Paulo: n-1 Edições, 2014.

PRIMO, Alex. Interações mediadas e remediadas: controvérsias entre as utopias da cibercultura e a grande indústria midiática. p. 13-32. In: PRIMO, Alex (org.). Interações em rede. Porto Alegre: Ed. Sulina, 2013. 
RAGO, Margareth. Feminizar é preciso: por uma cultura filógina. p. 58-66. São Paulo em Perspectiva, São Paulo, v. 15, n. 3, 2001. Disponível em https://bit.ly/2NBCztz. Acesso em abr. 2017.

RICH, Adrienne. Heterossexualidade compulsória e existência lésbica. p. 17-44. Bagoas - Estudos Gays: gênero e sexualidades, v. 4, n. 5, 2010. Disponível em https://bit.ly/2OkoSVg. Acesso em abr. 2017.

SANTAELLA, Lúcia. A ecologia pluralista da comunicação: conectividade, mobilidade, ubiquidade. São Paulo: Paulus, 2010.

SANTOS, Edméa. Educação online: cibercultura e pesquisa-formação na prática docente. Salvador, 2005. 351 f. Tese (Doutorado em Educação). Universidade Federal da Bahia. FACED-UFBA, Bahia, 2005. Disponível em https://bit.ly/2CLdUBY. Acesso em 13 out. 2018.

SANTOS, Marcelo Alves dos. Cartografia das redes da revolta: fluxos políticos de oposição radical no Facebook. p. 106-120. Contemporânea, Rio de Janeiro, v. 12, n. 2, 2014. Disponível em https://bit.ly/2OkQh9q. Acesso em 12 out. 2018.

SILVA, Tomaz Tadeu. Documentos de identidade: uma introdução às teorias do currículo. 3. ed. Belo Horizonte: Autêntica, 2010.

SILVEIRA, Sérgio Amadeu. Ciberativismo, cultura hacker e o individualismo colaborativo. p. 2839. Revista USP, São Paulo, v. 1, n. 86, jun./ago. 2010. Disponível em https://bit.ly/2fimSKt. Acesso em 12 out. 2018.

ZAGO, Gabriela da Silva, BATISTA, Jandré Corrêa. Ativismo e agendamento nos trending topics do Twitter: o caso Wikileaks. p. 101-114. Contemporânea, Comunicação e Cultura, Salvador, v. 9, n. 2, ago. 2011. Disponível em https://bit.ly/2ITgaar. Acesso em 12 out. 2018.

Submetido em outubro de 2019. Aprovado em janeiro de 2020.

\section{Informações do(as) autor(as)}

Dilton Ribeiro Couto Junior

Pós-doutorando (bolsista PNPD/CAPES) e Professor no Programa de Pós-Graduação em Educação, Cultura e Comunicação em Periferias Urbanas (PPGECC) da Universidade do Estado do Rio de Janeiro (UERJ/FEBF).

E-mail: junnior2003@yahoo.com.br

ORCID: http://orcid.org/0000-0002-5221-7135

Link Lattes: http://lattes.cnpq.br/3583771162535417

Luciana Velloso

Professora da Faculdade de Educação da Universidade do Estado do Rio de Janeiro (UERJ) e no

Programa de Pós-Graduação em Educação, Cultura e Comunicação em Periferias Urbanas (PPGECC) da $\mathrm{UERJ} / \mathrm{FEBF}$.

E-mail:1ucianavss@gmail.com

ORCID: https://orcid.org/0000-0002-6832-4189

Link Lattes: http://lattes.cnpq.br/5854415485261255 
DOI: https://doi.org/10.12957/teias.2020.48628

Rosemary dos Santos

Professora do Departamento de Formação de Professores da Faculdade de Educação da Universidade do Estado do Rio de Janeiro (UERJ/FEBF). Docente no Programa de Pós-Graduação em Educação, Cultura e Comunicação em Periferias Urbanas (PPGECC) da UERJ/FEBF e no Programa de Pós-graduação em Educação (ProPEd) da UERJ.

E-mail: rose.brisaerc@gmail.com

ORCID: http://orcid.org/0000-0003-0479-1703

Link Lattes: http://lattes.cnpq.br/9464170521679409 